\title{
Rösler investiert 8,5 Mio. Euro
}

$\mathrm{D}$ ie Rösler Oberflächentechnik $\mathrm{GmbH}$ investiert in den Ausbau des unterfränkischen Standorts Memmelsdorf 8,5 Mio. Euro. Ein Schwerpunkt ist dabei das Hochregallager, das termingerecht in der ersten Januar-Woche in Betrieb genommen wurde. Es bietet mit einer Grundfläche von 1400 Quadratmetern auf 17 Ebenen insgesamt 7741 Palettenstellplätze zum Einlagern von Grundstoffen, Schleifkörpern sowie Maschinen- und Ersatzteilen. Gerade im Bereich des After-Sales-Services möchte Rösler mit diesem Aufbau an Lagerkapazitäten noch schneller für den Kunden reagieren können. Pro Stunde können über die Lkw-Verladestation 100 Paletten aus- und eingelagert werden. Auch im Bereich der Produktion expandierte Rösler räumlich. Zwei Hallen mit einer Fläche von rund 3500 Quadratmetern sind im Herbst 2012 in Betrieb genommen worden. In diese Neubauten

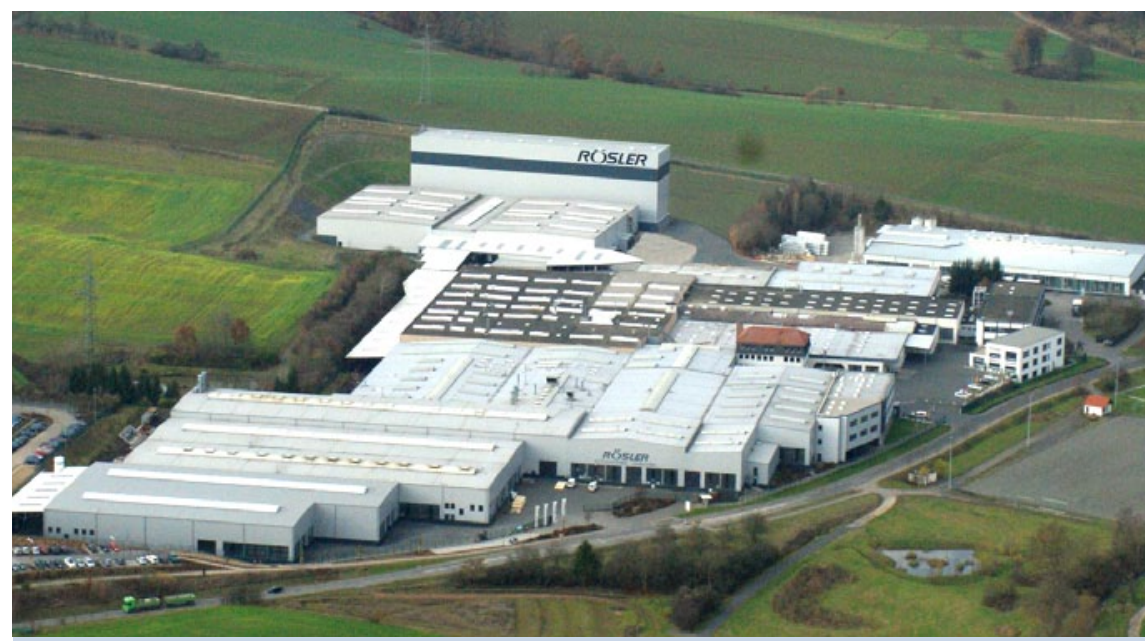

Das Rösler-Firmengelände in Memmelsdorf mit dem neuen Hochregallager (Bildmitte oben)

wurde im Wesentlichen der komplette Bereich der Laserfertigung verlagert. Dazu gehören die beiden vorhandenen Laserschneidanlagen mit einem dazugehörigen Materialkompaktla- ger. Neu hinzugekommen sind zwei Abkanntpressen mit jeweils 400 Tonnen Presskraft. Zum Investitionspaket gehörte auch der Bau von 240 neuen Mitarbeiter-Parkplätzen.
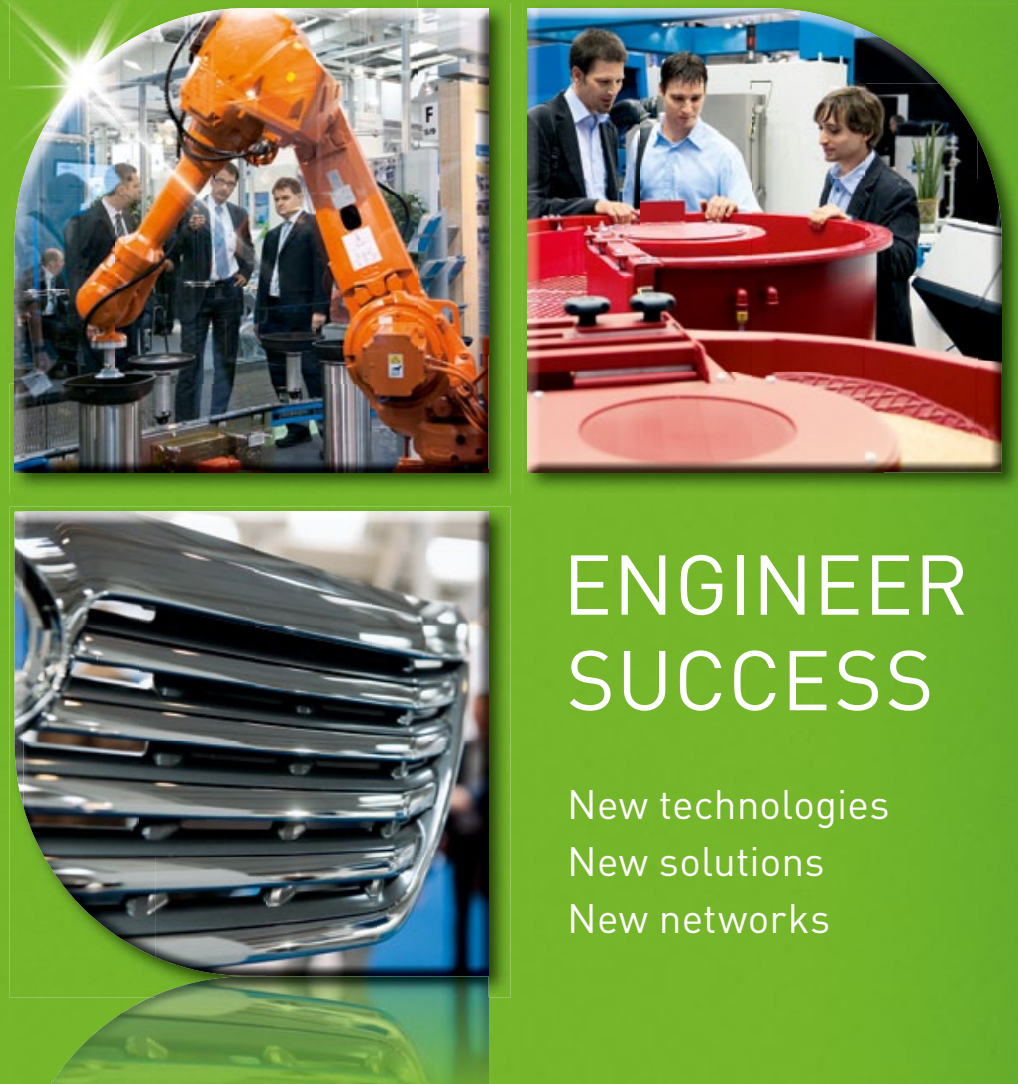

\section{New technologies}

New solutions

New networks

\section{Welche Oberflächen- technologien machen Ihre Produktion effizienter?}

\section{- Erleben Sie auf der internationalen Leitmesse für Oberflächentechnik techno- logische Innovationen für die Produktion von Beschichtungen sowie eine energie- schonende Oberflächenbehandlung. \\ - Als Branchentreffpunkt und Marktplatz für Wissenstransfer zeigt die SurfaceTechnology von der Vorbehandlung bis hin zur Lackier- und Galvanotechnik alle aktuellen Trends an einem Ort. \\ Besuchen Sie das weltweit wichtigste \\ Technologieereignis. \\ Mehr unter hannovermesse.de.}

Jetzt Termin vormerken: 8.-12. April 2013

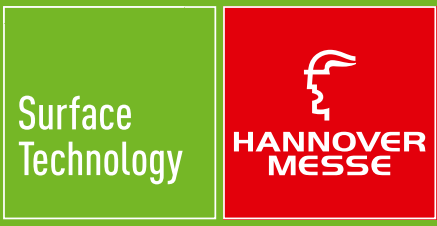

